Lawrence Berkeley National Laboratory report LBNL-56772

\title{
A Taxonomy of Integral Reaction Path Analysis
}

\author{
Joseph F. Grcar, Marcus S. Day, John B. Bell \\ Lawrence Berkeley National Laboratory \\ Mail Stop 50A-1148 \\ 1 Cyclotron Road \\ Berkeley, CA 94720-8142 USA \\ e-mail: jfgrcar@lbl.gov
}

\begin{abstract}
W. C. Gardiner observed that achieving understanding through combustion modeling is limited by the ability to recognize the implications of what has been computed and to draw conclusions about the elementary steps underlying the reaction mechanism. This difficulty can be overcome in part by making better use of reaction path analysis in the context of multidimensional flame simulations. Following a survey of current practice, an integral reaction flux is formulated in terms of conserved scalars that can be calculated in a fully automated way. Conditional analyses are then introduced, and a taxonomy for bidirectional path analysis is explored. Many examples illustrate the resulting path analysis and uncover some new results about nonpremixed methane-air laminar jets.
\end{abstract}




\section{Contents}

1 Introduction 3

2 Reaction Path Diagrams 3

2.1 Survey of Current Practice . . . . . . . . . . . . 3

2.2 Reaction Flux of Conserved Scalars . . . . . . . . . . . 5

2.3 Ambiguous Elementary Reactions . . . . . . . . . . 5

2.4 Example: Fuel Nitrogen . . . . . . . . . . . 7

3 Conditional Reaction Path Analysis $\quad 7$

3.1 Integrating over Subdomains . . . . . . . . . 7

3.2 Example: Conditioned by Stoichiometry . . . . . . 8

3.3 Example: Conditioned by Downstream Distance . . . 9

4 Bi-directional Reaction Paths 9

4.1 Five Types of Path Diagrams . . . . . . . . . . . 9

4.2 Example: Chain Branching . . . . . . . . . . 11

5 Software Tools 12

6 Conclusion $\quad 14$

$\begin{array}{ll}\text { Appendix. Simulation Data } & 14\end{array}$

$\begin{array}{ll}\text { Acknowledgments } & 15\end{array}$

$\begin{array}{ll}\text { References } & 15\end{array}$

$\begin{array}{ll}\text { Figures } & 19\end{array}$

$\begin{array}{ll}\text { Tables } & 27\end{array}$ 


\section{Introduction}

"Chemists interested in computer modeling are no longer limited by the constraints of computation. Instead, progress in achieving understanding of the reactions under study is limited by the ability to understand the implications of what has been computed and to draw inferences about the elementary reactions comprising the reaction mechanism. After completion of a modeling study, it is also a serious communication problem to convey the essential results and the justifications for the conclusions drawn - to other modeling experts or to the scientific community." [17, p. 2367]

The difficulties of interpretation and communication have increased since W. C. Gardiner described them in 1977. Then, direct numerical simulations with detailed chemistry were limited to well stirred reactors and shock tubes; today, they are of one-dimensional (1D) and 2D laminar flames, and even 3D turbulent flames $[4,33,40-42]$. Yet the primary means of data analysis and presentation have changed little: they are sensitivity and reaction path analyses, line and 2D plots of species concentrations, and scatter plots of probability density functions. Some new approaches are: computational singular perturbations $[10,28,30]$, which is related to principal component analysis, and stochastic particles [5], which is a random walk approximation to a Markov process representing the kinetics.

This paper examines the preparation of reaction path analyses and diagrams from multidimensional fluid dynamics calculations. Since the power of an analytical technique grows with the ability to apply it consistently and easily, the emphasis is on systematic approaches that can be accomplished wholly in software. Several examples uncover new facts about nonpremixed methane-air laminar jets.

This is the plan of the paper. Section 2 considers integral path analysis based on a conserved scalar approach to reaction fluxes. Section 3 introduces conditional analysis that is specific to certain flame zones. Section 4 considers analyses that capture the reversible nature of chemical reactions. It is found that there are several ways to calculate reversible integral fluxes, each with a different interpretation. Section 5 describes the software that created the reaction path diagrams in this paper. Section 6 summarizes the results. An Appendix briefly describes the simulations from which the examples are drawn.

\section{Reaction Path Diagrams}

\subsection{Survey of Current Practice}

Reaction path analysis is an accounting of the exchange of material among species in a chemically reacting system. The analysis is visualized by a reaction path diagram. In mathematical terms the diagram is a directed graph whose 
nodes are the chemical species. An edge connects two species if a reaction moves material from one to the other; the edge is drawn as an arrow from the reactant to the product. (This paper uses arrow, edge, and path interchangeably.) Diagrams that have edges connecting the same pair of species in opposite directions are discussed in Section 4.

To ground this discussion in a survey of actual practice, Figures 1 and 2 show reaction path diagrams from all fourteen papers that used them in Combustion and Flame during 2000. The diagrams are reproduced with their original captions and references to the originating authors.

Most diagrams are of a kind called "schematic" [11, p. 421, fig. 1] [34, p. 458, fig. 4] [44, p. 121, fig. 8.7] because they depict chemical mechanisms. Their arrows show the theoretically possible reactant-product dependencies provided by the elementary steps. Figure 1 contains examples of these. Thicker arrows may be used to indicate more important steps.

The diagrams of interest in this paper are those whose arrows impart quantitative information, as in Figure 2. The purpose of these diagrams, in contrast to schematics, is to prioritize the paths in a specific flame. Fluid dynamics modulates the chemistry by determining which reactions can progress and in what quantity. The thickness of an arrow may indicate the rate of material exchange among species.

In actual practice, several methods are used to determine the path weights. (This paper uses thickness, weight, and width interchangeably.) In Figure 2(a) the arrow thickness represents the molar flux of carbon-bearing species. In Figure 2(b) it represents the percent of all chlorine atoms in the system that react through the path. In Figure 2(c) the arrow thickness is based on sensitivity analysis $[27$, p. 606]. In Figure 2(d) it is the integral over the flame of the reaction rate of progress responsible for the path [29, pp. 269-270]. Since more than one reaction may account for the same arrow, this diagram has parallel arrows among some pairs of species. Lastly, the path weights in Figure 2(e) are not explained in [50].

Figures 2(a, b, d) quantify what has been called reaction flux [45, p. 128] or chemical flux (amount of substance transformed per unit volume per unit time), and they aggregate the quantity over space. This is called "integral" reaction path analysis [44, p. 95]. In contrast, Figure 2(c) is based on sensitivity analysis, that is, on derivative information.

Path analysis has an inherent indeterminacy when it is based on consumption or production of species, or on reaction rates of progress. The molar rate of consumption or production of species $s p_{k}$ in reaction $i$ is $\nu_{i, k} q_{i}$, where $\nu_{i, k}$ (nondimensional) is the stoichiometric coefficient and $q_{i}\left(\mathrm{~mol} / \mathrm{cm}^{3} \mathrm{~s}\right)$ is the reaction rate of progress. Reactions such as

$$
i: 2 \mathrm{CH}_{3} \rightleftharpoons \mathrm{C}_{2} \mathrm{H}_{6}
$$

give the path $\mathrm{CH}_{3} \rightarrow \mathrm{C}_{2} \mathrm{H}_{6}$ two weights: proportional either to $2 q_{i}$ if the consumption of $\mathrm{CH}_{3}$ is used, or to $q_{i}$ if either the production of $\mathrm{C}_{2} \mathrm{H}_{6}$ or the rate 
of progress is used. The ambiguity can be seen in Figure 2(d) where the arrow into $\mathrm{C}_{2} \mathrm{H}_{6}$ is twice thicker than the arrow out, and similarly in Figure 2(a) for the species $\mathrm{CF}_{2}=\mathrm{CH}_{2}$. In contrast, Figure 2(b) has no ambiguities because its weights are consistent with atomic conservation.

\subsection{Reaction Flux of Conserved Scalars}

This paper equates reaction flux with the "flow" of a conserved scalar through species due to reactions. Therefore each reaction path analysis is specific, for example, to a single element, typically carbon, nitrogen, or oxygen. With this in mind it is straightforward to determine the amount of material transformed by a reaction. Suppose reaction $i$ occurs,

$$
i: \mathrm{CH}_{4}+\mathrm{H} \rightleftharpoons \mathrm{CH}_{3}+\mathrm{H}_{2},
$$

in some infinitesimal region of space with volume $d V\left(\mathrm{~cm}^{3}\right)$. Let the nondimensional coefficient $n_{i}\left(\mathrm{C}, \mathrm{CH}_{4}, \mathrm{CH}_{3}\right)$ be the number of carbon atoms that a single forward instance of reaction $i$ moves from $\mathrm{CH}_{4}$ to $\mathrm{CH}_{3}$. For the stated reaction with the usual convention that the forward direction is from left to right, these numbers are $n_{i}\left(\mathrm{C}, \mathrm{CH}_{4}, \mathrm{CH}_{3}\right)=1$ while $n_{i}\left(\mathrm{C}, \mathrm{CH}_{3}, \mathrm{CH}_{4}\right)=-1$. A reaction path diagram for carbon then will have an edge between $\mathrm{CH}_{4}$ and $\mathrm{CH}_{3}$ whose contribution from reaction $i$ in this region of space is $n_{i}\left(\mathrm{C}, \mathrm{CH}_{4}, \mathrm{CH}_{3}\right) q_{i} d V$.

In aggregate (over the reactions and region of interest), atoms of element $e$ move from species $s p_{1}$ to species $s p_{2}$ at the rate

$$
N\left(e, s p_{1}, s p_{2}\right)=\sum_{i} \int_{V} n_{i}\left(e, s p_{1}, s p_{2}\right) q_{i} d V \quad(\mathrm{~mol} / \mathrm{s}),
$$

where the summation is over all reactions, and $V$ is the whole region of space. This number $N\left(e, s p_{1}, s p_{2}\right)$, or some scaling of it, becomes the width of the edge between species $s p_{1}$ and $s p_{2}$. The sign of the number determines the direction of the arrow: if positive then $s p_{1} \rightarrow s p_{2}$, if negative then $s p_{1} \leftarrow s p_{2}$.

The conserved scalar approach gives reaction path diagrams the following properties.

Property 1 . The amount of material removed from the species at the base of any path equals the amount contributed to the species at the head.

Property 2. The sum of the thicknesses of all paths into a species equals the sum of the thicknesses of all paths going out.

For species that flow into or out of the system, property 2 must also include boundary sources and sinks.

\subsection{Ambiguous Elementary Reactions}

The values of the coefficients $n_{i}\left(e, s p_{1}, s p_{2}\right)$ equal \pm 1 for many elements and reactions. Ambiguities do occur when the chosen element, $e$, is found in two 
reactants and two products. For example, the reaction in equation (1) removes a hydrogen atom from methane and binds it to the free hydrogen atom, resulting in the following redistribution of atoms.

$$
\begin{aligned}
& n_{i}\left(\mathrm{H}, \mathrm{CH}_{4}, \mathrm{CH}_{3}\right)=3 \\
& n_{i}\left(\mathrm{H}, \mathrm{CH}_{4}, \mathrm{H}_{2}\right)=1
\end{aligned}
$$

Without the knowledge that this is a hydrogen abstraction reaction, the following redistribution also is plausible because it too conserves atomic balance.

$$
\begin{aligned}
& n_{i}\left(\mathrm{H}, \mathrm{CH}_{4}, \mathrm{CH}_{3}\right)=2 \\
& n_{i}\left(\mathrm{H}, \mathrm{CH}_{4}, \mathrm{H}_{2}\right)=2
\end{aligned}
$$

Some early papers $[8,32]$ provide graphical depictions of reactions from which the disposition of individual atoms can be determined. As in this example, however, the usual manner of stating elementary reactions, by naming just their reactants and products, does not provide sufficient information to determine the numbers $n_{i}\left(e, s p_{1}, s p_{2}\right)$. Unfortunately, only this minimal information is included in the standard CHEMKIN [26] description of chemical mechanisms. Table 1 indicates the level of ambiguity in some well known reaction mechanisms.

Selecting the numbers $n_{i}\left(e, s p_{1}, s p_{2}\right)$ is equivalent to choosing a decomposition of the reacting molecules. The most general bimolecular reaction is a double exchange,

$$
\mathrm{Aa}+\mathrm{Bb} \rightleftharpoons \mathrm{Ab}+\mathrm{Ba},
$$

where $\mathrm{A}, \mathrm{B}, \mathrm{a}, \mathrm{b}$ are molecular fragments. Of the many such ways to express the four species in the reaction, there may be some in which one of $a$ or $b$ is absent. If this is so, then the reaction may actually be a single exchange,

$$
\mathrm{Aa}+\mathrm{B} \rightleftharpoons \mathrm{A}+\mathrm{Ba} .
$$

In either case, once the fragments have been identified, it is straightforward to determine the four coefficients for this reaction,

$$
n_{i}(e, \mathrm{Aa}, \mathrm{Ab}) \quad n_{i}(e, \mathrm{Aa}, \mathrm{Ba}) \quad n_{i}(e, \mathrm{Bb}, \mathrm{Ab}) \quad n_{i}(e, \mathrm{Bb}, \mathrm{Ba})
$$

For example, $n_{i}(e, \mathrm{Aa}, \mathrm{Ab})$ is the quantity of element $e$ in fragment $\mathrm{A}$.

In the absence of additional information an algorithm must be used to choose among the alternative species fragmentations. The following heuristic rules are used in this paper.

Rule 1. Prefer single exchanges over double exchanges.

Rule 2. Among single exchanges, prefer those that shuffle the fewest atoms, and among these with the same quantity of atoms, prefer those that shuffle the least atomic weight.

Rule 3. If possible preserve carbon-oxygen bonds by avoiding exchanges that separate carbon and oxygen atoms or that transfer a single carbon atom. 
These rules may well be incorrect for some reactions. For methane chemistry and carbon, nitrogen and oxygen, the ambiguities typically involve minor species whose reactions do not significantly contribute to the path weights. Thus the resolution of ambiguous cases has little impact on the analyses presented in this paper. Nevertheless this issue is generic to reaction path analysis and should be addressed with each new application.

\subsection{Example: Fuel Nitrogen}

The first set of examples compares "schematic" reaction path diagrams with those determined from flame simulations. These examples make the point that ranking the importance of several competing paths is not a purely chemical question but depends on which reactants the fluid can bring together in quantity to create a large reaction flux.

Figure 3 displays a standard schematic of ammonia oxidation. It is redrawn in Figure 4 with paths determined from the ammonia-seeded, methane diffusion flame calculation that is described in the Appendix. The path thicknesses are calculated by equation (2) for the element $e=\mathrm{N}$. Based on this data, the paths through $\mathrm{N}$ are the most important. Note that ammonia is the ultimate source of the atomic nitrogen in this flame. Molecular nitrogen also could be a source, but nitrogen dilution of the fuel limits the temperature to barely more than the $1800 \mathrm{~K}$ needed for the thermal (Zeldovich) mechanism. The prompt (Fenimore) is not a major contributor here but the carbon chemistry does play a role.

The unterminated arrows in Figure 4 are paths through carbon-nitrogen species. The complete nitrogen reaction path diagram is shown in Figure 5. Evidently some nitrogen atoms cycle between carbon-bearing and carbon-free species before leaving the flame as either nitric oxide or molecular nitrogen. The reactions responsible for the various paths are identified in [39]. A stochastic particle analysis of the computational results is given in [5]. There, the cycling in the path diagram is found to correspond to a spatial migration of nitrogen atoms that alternate between different molecules on the rich and lean sides of the diffusion flame sheet while flowing from the base to the tip.

\section{Conditional Reaction Path Analysis}

\subsection{Integrating over Subdomains}

Reaction paths can be qualified by various conditions. Equation (2) expresses the fluxes as volume integrals over a region of space. If the integration is limited to part of the region, then the integration is premised by the condition that picks out the desired subregion. These conditional reaction path diagrams are helpful in elucidating fluid-chemistry interactions. A diagram may be conditioned by some property of the fluid, which permits an investigation of the flame chemistry supported by just that fluid regime. 
Moreover, for a condition giving a certain fluid property, the complementary condition can be used to create a second diagram. Comparing the two diagrams then reveals how the fluid property in question affects the flame chemistry. An effective way to compare two diagrams is to draw them coincidentally. In this approach, the two diagrams share the same nodes, but their arrows are drawn in different colors.

\subsection{Example: Conditioned by Stoichiometry}

The first example of conditional reaction path diagrams contrasts the carbon chemistry on the fuel and oxygen rich sides of a methane diffusion flame. This requires conditions that identify the lean and rich mixtures.

For combustion in which there are two identifiable streams, it has become customary to measure the extent of mixing, at any given point in the fluid, by a mixture fraction of the atoms that originate in one stream. The fraction may be a ratio either of moles [23] or more commonly of masses [7] in which case it is given the symbol $\xi$. However, several different formulas have been given for $\xi$, see for example [38, p. 578, eqn. 5.3] and [44, p. 133, eqn. 9.9], so evidently it is not straightforward to determine mixture fractions conclusively from the quantities available in a flame calculation.

It is more convenient to use the following simple expression. Let $\{e\}$ be the molar concentration of element $e$ at a point in the mixture (all the atoms in all the molecules), and similarly let $z_{e}$ be the elemental mole fraction (note $Z_{e}$ is already used for the elemental mass fraction [44]). The ratio,

$$
\psi=\frac{4\{\mathrm{C}\}+1\{\mathrm{H}\}}{4\{\mathrm{C}\}+1\{\mathrm{H}\}+2\{\mathrm{O}\}}=\frac{4 z_{\mathrm{C}}+1 z_{\mathrm{H}}}{4 z_{\mathrm{C}}+1 z_{\mathrm{H}}+2 z_{\mathrm{O}}},
$$

varies from 0 in mixtures with only oxidizer atoms, through $1 / 2$ at stoichiometric mixtures, to 1 in mixtures with only fuel. Therefore the conditions $\psi<$, =, and $>1 / 2$ respectively identify lean, stoichiometric, and rich mixtures in any hydrocarbon-air fluid. This $\psi$ is similar to but different from the fuel equivalence ratio, $\phi$, which is a mass ratio and includes nitrogen. The coefficients in $\psi$ are the quantities of bonds for the various atoms.

Diffusion flames are known to lie at or slightly to the rich side of the stoichiometric zones in their mixtures. Figure 6(a) confirms this for the flame described in the Appendix. The temperature can be seen to peak just to the rich side of the stoichiometric surface. Moreover, it is known that the flame's alignment is reflected in the chemistry. In the earliest fully $2 \mathrm{D}$ simulations of diffusion flames with detailed chemistry, Smooke et al. [38, p. 581] observed that $\mathrm{CO}_{2}$ forms only in the lean, outer layers. They explained the phenomenon by an analysis due to Westbrook and Dryer [38, p. 580] [46].

The observation of Smooke et al. can be strengthened by conditional reaction path analysis. Figure 7 displays conditional carbon reaction path diagrams for the lean and rich sides of the flame in Figure 6. The condition $\psi<1 / 2$ 
determines the lean paths which are colored blue, while $\psi>1 / 2$ determines the rich paths which are colored red. These diagrams both graphically depict the observation of Smooke et al. and support a stronger conclusion. The final step, $\mathrm{CO} \rightarrow \mathrm{CO}_{2}$, occurs almost completely on the lean side, while all other reactions involving carbon-bearing species occur almost completely on the rich side. Thus the stoichiometric surface corresponds to a dichotomy in the oxidation chemistry that neatly separates the final reaction step from all the others.

\subsection{Example: Conditioned by Downstream Distance}

The second example of conditional reaction path diagrams compares the reactions at the base with those further downstream in a laminar jet diffusion flame.

These flames have a rich spatial structure [6]. Several flame sheets extend from a common ignition point, and may close at much different heights above the fuel nozzle, or may remain open. For example, Figure 6(b) shows two flame sheets closing on the rich side at centerline heights of 2.0 and $3.3 \mathrm{~cm}$, while one flame sheet remains open on the lean side. Additionally, the concentration of the primary fuel species typically becomes negligible a small distance downstream of the flame base. Figure 8(a) shows that the centerline mole fraction of methane drops by two orders of magnitude over a distance of $1-2 \mathrm{~cm}$. If the contours were not drawn on a log scale it would be difficult to see any methane beyond this point, consistent with observations of similar flames [37, p. 2165] [38, p. 579]. At the same time, both fuel and oxidizer leak into the other fluid upstream of the ignition point, as shown in Figure 8. These observations leave the cumulative impression that different reactions may be encountered downstream than at the base of the flame.

To examine whether this hypothesis may be true, Figure 9 displays carbon reaction path diagrams for the lower and higher parts of the flame. The condition $z \leq 1$ determines the lower paths which are colored red; the condition $z>1$ determines the upper paths which are colored blue $(z$ is the axial coordinate of position). This picture reveals that the major carbon pathways are mirrored above and below the $z=1 \mathrm{~cm}$ altitude. The only difference apparent among the major paths is the slightly disproportionate emphasis of the final step $\mathrm{CO} \rightarrow$ $\mathrm{CO}_{2}$ indicating that some carbon monoxide produced at the base is consumed further above. Given the complicated spatial structure of the flame, reaction path diagrams conditioned on individual flame zones may be quite different. In bulk, however, Figure 9 shows that reaction paths at the base are qualitatively, and nearly quantitatively, the same as those downstream.

\section{Bi-directional Reaction Paths}

\subsection{Five Types of Path Diagrams}

This section examines using reaction path analysis to represent the reversible nature of reactions. It is surprisingly complicated to determine weights that 
convey the most useful information. Following a technical analysis of modifications to the weight formula, the possibilities are illustrated by studying chain branching.

In equation (2), the sign of the reaction rate of progress, $q_{i}$, may vary over the computational domain. The changes can occur because the rate of progress is a difference of rates for the reaction's forward and reverse directions, $q_{i}=$ $q_{i}^{(f)}-q_{i}^{(r)}$, where both $q_{i}^{(f)}$ and $q_{i}^{(r)}$ are positive.

The simplest way to account for reversibility is to separately tabulate the reaction fluxes cause by the forward and reverse directions of each reaction. This produces forward and reverse arrows that indicate the molar rate of movement of atoms in each direction. The weight in the direction $s p_{1} \rightarrow s p_{2}$ is,

$$
\begin{aligned}
N_{0}^{(f)}\left(e, s p_{1}, s p_{2}\right) & =\sum_{i} \int_{V} \operatorname{pos}\left(n_{i}\left(e, s p_{1}, s p_{2}\right) q_{i}^{(f)}\right) d V \\
& +\sum_{i} \int_{V} \operatorname{pos}\left(-n_{i}\left(e, s p_{1}, s p_{2}\right) q_{i}^{(r)}\right) d V
\end{aligned}
$$

where $\operatorname{pos}(\cdot)$ is a function whose value is its argument if that is positive, and is zero if negative. Equation (5) can be written more simply if the forward and reverse directions are considered to be separate reactions with rates of progress $q_{i}^{(f)}$ and $q_{i}^{(r)}$ and with coefficients $n_{i}$ and $-n_{i}$, respectively. Let $\widetilde{n}_{i}$ and $\widetilde{q}_{i}$ be the coefficients and rates of progress of these unidirectional reactions. (They number twice the reversible reactions, but the same subscript, $i$, is used for both.) This notation simplifies equation (5) to

$$
N_{0}^{(f)}\left(e, s p_{1}, s p_{2}\right)=\sum_{i} \int_{V} \operatorname{pos}\left(\widetilde{n}_{i}\left(e, s p_{1}, s p_{2}\right) \widetilde{q}_{i}\right) d V
$$

where $i$ ranges over the unidirectional reactions. Similarly, the reverse direction has negative weight,

$$
\begin{aligned}
N_{0}^{(r)}\left(e, s p_{1}, s p_{2}\right) & =\sum_{i} \int_{V} \operatorname{neg}\left(\widetilde{n}_{i}\left(e, s p_{1}, s p_{2}\right) \widetilde{q}_{i}\right) d V \\
& =-N_{0}^{(f)}\left(e, s p_{2}, s p_{1}\right) .
\end{aligned}
$$

Note the forward and reverse weights coalesce to equation (2),

$$
N\left(e, s p_{1}, s p_{2}\right)=N_{0}^{(f)}\left(e, s p_{1}, s p_{2}\right)+N_{0}^{(r)}\left(e, s p_{1}, s p_{2}\right) .
$$

The constituent weights have been labeled with a subscript 0 because they are the simplest generalizations of equation (5). The resulting "type 0" reaction path diagrams coalesce no opposed fluxes and so display the widest possible paths.

Different degrees of coalescence can be obtained by using either reversible $\left(n_{i}, q_{i}\right)$ or unidirectional $\left(\widetilde{n}_{i}, \widetilde{q}_{i}\right)$ quantities in Equations $(6)$ and $(7)$, and by 
permuting the order of the operators $\sum, \int$ and pos (or neg) in the formulas. There are 2 choices of quantities and $3 !=6$ permutations of the 3 operators, resulting in a total of 12 choices. Many choices give the same fluxes due to the following algebraic identities:

$$
\sum \int=\int \sum, \quad \int \operatorname{pos} \tilde{n} \widetilde{q}=\operatorname{pos} \int \tilde{n} \widetilde{q}, \quad \sum \widetilde{n} \widetilde{q}=\sum n q .
$$

Altogether, there are only five distinct sets of reaction path weights.

$$
\begin{array}{ll}
\text { (type } 0) & \int \sum \operatorname{pos} \widetilde{n} \widetilde{q}=\sum \int \operatorname{pos} \widetilde{n} \widetilde{q}=\sum \operatorname{pos} \int \widetilde{n} \widetilde{q} \\
\text { (type 1) } & \int \sum \operatorname{pos} n q=\sum \int \operatorname{pos} n q \\
\text { (type } 2) & \sum \operatorname{pos} \int n q \\
\text { (type } 3) & \int \operatorname{pos} \sum \widetilde{n} \widetilde{q}=\int \operatorname{pos} \sum n q \\
\text { (type } 4) & \operatorname{pos} \sum \int \tilde{n} \widetilde{q}=\operatorname{pos} \int \sum \widetilde{n} \widetilde{q}=\operatorname{pos} \int \sum n q=\operatorname{pos} \sum \int n q
\end{array}
$$

The corresponding reverse fluxes are evaluated by replacing pos with neg in these formulas. The resulting 5 reaction path diagrams, of types 0 through 4 , convey the following information.

Type $0 . \sum \int \operatorname{pos} \tilde{n} \widetilde{q}$, not coalesced. These are given by equation (5). Bidirectional arrows always occur for this case because the forward and reverse parts of each reaction are treated separately.

Interestingly, the remaining cases can be formulated without decomposing reactions into forward and reverse parts.

Type 1. $\sum \int \operatorname{pos} n q$, any reactions anywhere. Bidirectional paths occur here if any one or more reactions move material in opposite directions anywhere in the flame.

Type 2. $\sum \operatorname{pos} \int n q$, different reactions. This formula integrates the contribution of each reaction over space before summing the reactions. Hence if bidirectional paths occur, then two or more reactions are moving material in opposite directions.

Type 3. $\int \operatorname{pos} \sum n q$, different places. The reaction flux net of all reactions is formed at each point before integrating. If bidirectional paths occur, then the flux has different directions at different locations.

Type 4. $\operatorname{pos} \int \sum n q$, unidirectional. These are given by equation (2).

\subsection{Example: Chain Branching}

Chains of reaction steps that produce and consume radical populations underlie all combustion processes. This example uses bidirectional path diagrams to investigate chaining reactions. 
Chain branching is usually discussed with reference to a specific fuel, but since the common ingredient is the oxidizer, Figure 10 displays path diagrams for oxygen in the flame used as an example throughout this paper. All five types of path analyses in the taxonomy are shown. The scale of Figure 10(a) is not the same as the others because type 0 diagrams show both directions of reversible reactions so they have much thicker arrows. Some opposed paths are so thick that it is difficult to see the net direction or smaller paths. From this it is clear a more useful indicator of bidirectionality is the type 1 diagram which coalesces the forward and reverse direction of each reaction.

Only two paths have large opposed directions, $\mathrm{O}_{2} \leftrightarrow \mathrm{HO}_{2}$ and $\mathrm{OH} \leftrightarrow \mathrm{H}_{2} \mathrm{O}$. The similarity of the diagrams of types 1 and 2 in Figure 10, and again of types 3 and 4 , indicates that most of the reversibility is due to different reactions. Table 2 lists the major reactions that account for each arrow in Figure 10(b). This shows that the bidirectional path $\mathrm{O}_{2} \leftrightarrow \mathrm{HO}_{2}$ consists of the third-body assisted step $\mathrm{H}+\mathrm{O}_{2} \rightarrow \mathrm{HO}_{2}$ that is reversed by three parallel reactions $\mathrm{O}_{p} \mathrm{H}_{q}+\mathrm{HO}_{2} \rightarrow$ $\mathrm{H}_{q+1} \mathrm{O}_{p}+\mathrm{O}_{2}$ where $1 \leq p+q \leq 2$.

The other major bidirectional path, $\mathrm{OH} \leftrightarrow \mathrm{H}_{2} \mathrm{O}$, is surprisingly strong in a direction that consumes a final product. Table 2 shows that the forward path reacts $\mathrm{OH}$ with molecular hydrogen and to a lesser extent with methane and formaldehyde, while the reverse reacts water with oxygen atoms and to a lesser extent with hydrogen atoms. Some of the most active radicals thus are lost in decomposing water. The path that consumes water occurs on the centerline below the middle flame sheet shown in Figure 6(b). This is a very warm region where some mildly endothermic carbon reactions also occur [39].

Figure 10 reveals the interesting fact that virtually all oxygen atoms pass through hydroxyl. Thus the diagram divides into paths below $\mathrm{OH}$ mostly involving carbon species and forming final products, and paths above $\mathrm{OH}$ caused mostly by hydrogen-oxygen chain branching. Since the chaining reactions are vigorous and occur among just a few species, they are likely to work at cross purposes. It is therefore a priori uncertain which reactions predominate in an actual flame. Table 3 lists the hydrogen-oxygen reactions found in Table 2 prioritized by their contribution to the type 1 paths of Figure 10(b). Many of these reactions have been cited in discussions of hydrogen oxidation $[19,43,44,48]$, however, one has been overlooked and another unexpectedly reverses direction.

\section{Software Tools}

Software to display reaction path diagrams is freely available from the authors [14]. Preparing reaction path diagrams from computer simulations divides naturally into three parts.

The first step evaluates integrals (or conditional integrals) of reaction rates of progress over the simulation domain. For example, the diagrams in Figures 
$4,5,7,9$, and $10(\mathrm{e})$ require Equation (2)'s volume integrals,

$$
\begin{aligned}
N\left(e, s p_{1}, s p_{2}\right) & =\sum_{i} \int_{V} n_{i}\left(e, s p_{1}, s p_{2}\right) q_{i} d V \\
& =\sum_{i}\left(n_{i}\left(e, s p_{1}, s p_{2}\right) \int_{V} q_{i} d V\right) .
\end{aligned}
$$

The integrals $\int_{V} q_{i} d V$ are best performed in the software framework of the fluid simulation where the data structures for the mesh and dependent variables, and the software to evaluate the reaction rates of progress, are available. The resulting integrals are simply a list of numbers, one for each reaction, that can be written to a small file.

Second, the integrals $\int_{V} q_{i} d V$ must be combined in Equation (8) with the coefficients $n_{i}\left(e, s p_{1}, s p_{2}\right)$ to give the path weights $N\left(e, s p_{1}, s p_{2}\right)$. This is straightforward provided the coefficients are known. A function is available for use in the python scripting language [1] that determines the coefficients by the method of Section 2.3, for a given element $e$ and a given chemical mechanism. The coefficients are listed by species pairs, $\left(s p_{1}, s p_{2}\right)$. For each such pair, there is a sublist of reaction indices, $i$, and coefficients, $n_{i}$, that contribute to the path $s p_{1} \rightarrow s p_{2}$. When combined with the integrals, the result is a list of paths consisting of two species names, $\left(s p_{1}, s p_{2}\right)$, and a weight for the path, $N\left(e, s p_{1}, s p_{2}\right)$. This again is a short list of alphanumeric data that can be written to a file.

The final step is to draw the path diagram given the species names and the weights of the paths. Some care must be taken at this step to best communicate the information contained in the data. The chemical networks can be arbitrarily complex with the resulting diagrams potentially dominated by hundreds of insignificant edges connecting trace species. It is usually necessary to explore diagram layouts by varying the edges shown (level of detail) and the placement of nodes. As in this paper it is also helpful to draw several diagrams in the same format to facilitate comparison.

There are visualization tools for directed graphs, such as GraphViz [15], that automatically place nodes and route edges. These software tools arrange graphs to minimize visual complexity subject to constraints on the extent to which edges may curve around parts of the diagrams. The disadvantage for drawing reaction paths is that each data set generates a unique layout. Visual comparisons between similar data sets becomes difficult even for chemical systems of only moderate complexity.

A graph drawing tool has been developed with a graphical user interface to allow a level of user control more appropriate for reaction path diagrams. The nodes are placed on a drawing "canvas" and may be interactively manipulated with the edges dynamically following the nodes as they are adjusted. The resulting diagrams can be edited, saved, redrawn with new datasets, and exported to postscript format. The software is available at [13] and was used to generate all of the reaction path diagrams in this paper. 


\section{Conclusion}

Current practice regarding integral reaction path analysis is surveyed. An approach based on a definition of chemical or reactive flux in terms of conserved scalar quantities is described at length, including methods to overcome the indeterminacy resulting from CHEMKIN-style specifications of elementary reaction steps. Conditional reaction path analysis is introduced and used to examine the carbon chemistry of nonpremixed methane-air laminar jets. It is found that the stoichiometric surface divides the final carbon oxidation step from the others, and contrary to what might be inferred from the literature, there is no significant difference between the paths active at the ignition point and further downstream. Further, path analyses that reveal the reversible nature of elementary reactions are examined. It is found that five unique analyses are possible, which can be distinguished by whether they indicate reversibility occurs at different spatial locations or is caused by elementary steps acting in opposition at the same location. Reversible oxygen paths in a nonpremixed methane-air laminar jet are found to channel virtually all oxygen through the hydroxyl radical, to expend large radical populations in decomposing water, and to involve some chaining reactions not discussed in combustion textbooks.

\section{Appendix. Simulation Data}

This paper's examples are produced from two-dimensional simulations of a nonpremixed methane-air laminar jet, otherwise known as a Burke-Schumann flame [9]. An earlier paper [39] describes the simulations and compares them with experimental data.

Briefly, the flame burns at the base of a vertical quartz tube that has a radius of $1.4 \mathrm{~cm}$ and an axial length of $76 \mathrm{~cm}$ (only $11 \mathrm{~cm}$ are treated in the computation); the fuel nozzle at the lower edge of the tube has an inner radius of $0.6 \mathrm{~cm}$ and an outer radius of $0.7 \mathrm{~cm}$. The coflowing oxidizer is a mixture of oxygen and nitrogen at flow rates of 840 and $3160(\mathrm{~mL} / \mathrm{min})$. The fuel is a mixture of methane and nitrogen at flow rates of 150 and $220(\mathrm{~mL} / \mathrm{min})$, respectively. When ammonia is added to the fuel, it is in the amount of 1000 ppm of the total fuel-oxidizer inflow. The nitrogen dilution of the fuel results in a cool flame; the reaction path diagrams presented here may not be representative of hotter flames. The flame is modeled using the chemical mechanism of 66 species and 447 reactions of Glarborg et al. [18] for methane flames with nitrogen chemistry. The algorithm described by Day and Bell [12] is used to advance the reacting flow equations in time to a steady-state. The solution algorithm includes adaptive mesh refinement (AMR) to resolve details of the thin flame structures. 


\section{Acknowledgments}

Thanks to Dr. W. Y. Crutchfield for help with the python programming language, to Prof. P. Glarborg for helping to develop the heuristic rules for the disposition of atoms from reactant to products, and to Prof. D. G. Goodwin for help in developing the approach based on conserved scalars, which is also used in Cantera applications [22].

\section{References}

[1] Anonymous. The official website for the python language. http://www.python.org/, 2002.

[2] J. Appel, H. Bockhorn, and M. Frenklach. Kinetic modeling of soot formation with detailed chemistry and physics: Laminar premixed flames of $\mathrm{C}_{2}$ hydrocarbons. Combustion and Flame, 121:122-136, 2000.

[3] K. H. Becker, R. Kurtenbach, F. Schmidt, and P. Wiesen. Kinetics of the NCO radical reacting with atoms and selected molecules. Combustion and Flame, 120:570-577, 2000.

[4] J. B. Bell, M. S. Day, and J. F. Grcar. Numerical simulation of premixed turbulent methane combustion. Proc. Combust. Inst., 29:1987-1993, 2002.

[5] J. B. Bell, M. S. Day, J. F. Grcar, and M. J. Lijewski. Stochastic algorithms for the analysis of numerical flame simulations. J. Comput. Phys., 202:262-280, 2005.

[6] B. A. V. Bennett, C. S. McEnally, L. D. Pfefferle, M. D. Smooke, and M. B. Colket. Computational and experimental study of axisymmetric coflow partially premixed ethylene/air flames. Combust. Flame, 127:2004-2022, 2001.

[7] R. W. Bilger. Turbulent jet diffusion flames. Prog. Energy Combust. Sci., $1(2-3): 87-109,1976$.

[8] M. C. Branch, R. J. Kee, and J. A. Miller. A theoretical investigation of mixing effects in the selective reduction of nitric oxide by ammonia. Combust. Sci. Tech., 29:147-165, 1982.

[9] S. P. Burke and T. E. W. Schumann. Diffusion flames. Ind. Engin. Chem., 20(10):998-1004, 1928.

[10] A. Chrissanthopoulos, G. Skevis, and E. Mastorakos. Analysis of methane-air flame structures near extinction limits using CSP. In proceedings of the Fourth GRACM Congress on Computational Mechanics, 2002. Patra, June 27-29. 
[11] A. D'Anna, A. Violi, and A. D'Alessio. Modeling the rich combustion of aliphatic hydrocarbons. Combustion and Flame, 121:418-429, 2000.

[12] M. S. Day and J. B. Bell. Numerical simulation of laminar reacting flows with complex chemistry. Combust. Theory Modelling, 4:535-556, 2000.

[13] M. S. Day and J. F. Grcar. Chemical reaction path diagram tool. ttp://seesar.lbl.gov/CCSE/Software/README_cemPathTool.htm.

[14] M. S. Day and J. F. Grcar. Reaction path diagram software. http://seesar.lbl.gov/ccse/Software/README_chemPathTool.htm, 2002.

[15] J. Ellison and S. North. Graphviz - graph visualization software. ttp://www.grapviz.org/.

[16] A. Fontijn, A. Goumri, and P. E. Brock II. Pressure-dependence of the $\mathrm{CO}\left(\mathrm{d}^{3} \Delta-\mathrm{a}^{3} \Pi\right)$ triplet bands chemiluminescence intensities from the $\mathrm{O}+$ $\mathrm{C}_{2} \mathrm{H}_{2}$ reaction: Mechanistic implications. Combustion and Flame, 121:699-701, 2000.

[17] W. C. Gardiner, Jr. The pc, pr, pm, and ps method of formulating the results of computer modeling studies of chemical reactions. The Journal of Computational Chemistry, 81:2367-2371, 1977.

[18] P. Glarborg, M. U. Alzueta, K. Dam-Johansen, and J. A. Miller. Kinetic modelling of hydrocarbon/nitric oxide interactions in a flow reactor. Combust. Flame, 115:1-27, 1998.

[19] I. Glassman. Combustion. Academic Press, third edition, 1996.

[20] P. A. Glaude, F. Battin-Leclerc, B. Judenherc, V. Warth, R. Fournet, G. M. Côme, G. Scachhi, P. Dagaut, and M. Cathonnet. Experimental and modeling study of the gas-phase oxidation of methyl and ethyl tertiary butyl ethers. Combustion and Flame, 121:345355, 2000.

[21] A. Goldaniga, T. Faravelli, and E. Ranzi. The kinetic modeling of soot precursors in a butadiene flame. Combustion and Flame, 122:350-358, 2000 .

[22] D. G. Goodwin. MixMaster, a Cantera application. http://rayleigh. cds.caltech.edu/ goodwin/cantera/documentation.html.

[23] W. R. Hawthorne, D. S. Weddell, and H. C. Hottel. Proc. Combust. Inst., 3:266, 1949. Proceedngs of the Symposium on Combustion and Flame, and Explosion Phenomena, September 7-11, 1948.

[24] K. J. Hughes, T. Turányi, A. Clague, and M. J. Pilling. Development and testing of a comprehensive chemical mechanism for the oxidation of methane. Int. J. Chem. Kinet., 33:513-538, 2001. version 1.5, http://www. chem. leeds.ac.uk/Combustion/methane.htm. 
[25] A. Kazakov and M. Frenklach. Reduced reaction sets based on GRI-Mech 1.2. http://www.me.berkeley.edu/drm/.

[26] R. J. Kee, R. M. Ruply, E. Meeks, and J. A. Miller. Chemkin-III: A FORTRAN chemical kinetics package for the analysis of gas-phase chemical and plasma kinetics. Sandia National Laboratories Report SAND96-8216, Sandia National Laboratories, Livermore, 1996.

[27] O. P. Korobeinichev, S. B. Ilyin, T. A. Bolshova, V. M. Shvartsberg, and A. A. Chernov. The chemistry of the destruction of organophosphorus compounds in flames-III: The destruction of DMMP and TMP in a flame of hydrogen and oxygen. Combustion and Flame, 121:593-609, 2000.

[28] S. H. Lam and D. A. Goussis. Understanding complex chemical kinetics with computational singular perturbation. Proc. Comb. Inst., 22:pp. $931+, 1988$.

[29] J. Lim, J. Gore, and R. Viskanta. A study of the effects of air preheat on the structure of methane/air counterflow diffusion flames. Combustion and Flame, 121:262-274, 2000.

[30] A. Massias, D. Diamantis, E. Masorakos, and D. A. Gousis. An algorithm for the construction of global reduced mechanisms with CSP data. Combustion and Flame, 117:685-708, 1999.

[31] J. A. Miller and C. T. Bowman. Mechanism and modeling of nitrogen chemistry in combustion. Prog. Energy Combust. Sci., 15(4):287-338, 1989 .

[32] J. A. Miller, M. D. Smooke, R. M. Green, and R. J. Kee. Kinetic modeling of the oxidation of ammonia in flames. Combust. Sci. Tech., 34:149-176, 1983.

[33] Y. Mizobuchi, S. Tachibana, J. Shinio, S. Ogawa, and T. Takeno. A numerical analysis of the structure of a turbulent hydrogen jet lifted flame. Proc. Combust. Inst., 29:2009-2015, 2002.

[34] M. D. Rumminger and G. T. Linteris. Inhibition of premixed carbon monoxide-hydrogen-oxygen-nitrogen flames by iron pentacarbonyl. Combustion and Flame, 120:451-464, 2000.

[35] L. A. Sgro, C. P. Koshland, D. Lucas, and R. F. Sawyer. Postflame reaction chemistry of dichloromethane: Variations in equivalence ratio and temperature. Combustion and Flame, 120:492-503, 2000.

[36] G. P. Smith, D. M. Golden, M. Frenklach, N. W. Moriarty, B. Eiteneer, M. Goldenberg, C. T. Bowman, R. K. Hanson, S. Song, W. C. Gardiner Jr., V. V. Lissianski, and Z. Qin. GRI-Mech 3.0. http://www.me.berkeley.edu/gri_mech/. 
[37] M. D. Smooke, A. Ern, M. A. Tanoff, B. A. Valdati, R. K. Mohammed, D. F. Marran, and M. B. Long. Computational and experimental study of NO in an axisymmetric laminar diffusion flame. Proc. Combust. Inst., 26:2161-2170, 1996.

[38] M. D. Smooke, P. Lin, J. K. Lam, and M. B. Long. Computational and experimental study of a laminar axisymmetric methane-air diffusion flame. Proc. Combust. Inst., 23:575-582, 1990.

[39] N. Sullivan, A. Jensen, P. Glarborg, M. S. Day, J. F. Grcar, J. B. Bell, C. Pope, and R. J. Kee. Ammonia conversion and $\mathrm{NO}_{x}$ formation in laminar coflowing nonpremixed methane-air flames. Combust. Flame, 131:285-298, 2002.

[40] M. Tanahashi, M. Fujimura, and T. Miyauchi. Coherent fine scale eddies in turbulent premixed flames. Proc. Combust. Inst., 28:529-535, 2000.

[41] M. Tanahashi, Y. Nada, Y. Ito, and T. Miyauchi. Local flame structure in the well-stirred reactor regime. Proc. Combust. Inst., 29:2041-2049, 2002.

[42] N. Tsuboi, S. Katoh, and A. K. Hayashi. Three-dimensional numerical simulations for hydrogen/air detonation: rectangular and diagonal structures. Proc. Combust. Inst., 29:2783-2788, 2003.

[43] S. R. Turns. An Introduction to Combustion. McGraw-Hill, New York, second edition, 2000.

[44] J. Warnatz, U. Maas, and R. W. Dibble. Combustion. Springer-Verlag, Berlin, 3rd edition, 2001.

[45] J. H. Werner and T. A. Cool. The kinetics of the combustion of trichloroethylene for low $\mathrm{Cl} / \mathrm{H}$ ratios. Combustion and Flame, 120:125-142, 2000.

[46] C. K. Westbrook and F. L. Dryer. Prog. Energy Comb. Sci., 10:1, 1984.

[47] B. A. Williams, D. M. L'Espérance, and J. W. Fleming. Intermediate species profiles in low-pressure methane/oxygen flames inhibited by $2-\mathrm{H}$ heptafluoropropane: Comparison of experimental data with kinetic modeling. Combustion and Flame, 120:160-172, 2000.

[48] F. A. Williams. Combustion Theory. Addison-Wesley, Menlo Park, 2nd edition, 1988.

[49] Y.-P. Wu and Y.-S. Won. Pyrolysis of chloromethanes. Combustion and Flame, 122:312-326, 2000.

[50] E. J. P. Zegers, B. A. Williams, E. M. Fisher, J. W. Fleming, and R. S. Sheinson. Suppression of nonpremixed flames by fluorinated ethanes and propanes. Combustion and Flame, 121:471-487, 2000. 


\section{List of Figures}

1 Nine "schematic" reaction path diagrams from Combustion and Flame in 2000. . . . . . . . . . . . . . . . . . . . . .

2 Five "quantitative" reaction path diagrams from Combustion and Flame in 2000. . . . . . . . . . . . . . . . . . 21

3 A familiar schematic of ammonia oxidation. This originated in [32] and was redrawn with slight changes in [31]. . . . . . . . . 22

4 The schematic in Figure 3 is here redrawn with nitrogen reaction paths for an actual methane diffusion flame with ammonia seeding. The unterminated arrows represent paths to or from carbon species. The largest reaction flux is $\mathrm{NH}_{2} \rightarrow \mathrm{NH}$ at $4.2 \mathrm{e}-6(\mathrm{~mol} / \mathrm{s})$. Only arrows at least $3 \%$ of the thickest are drawn. Figure 5 shows the complete diagram. . . . . . . . . . . . .

5 Nitrogen reaction paths in a methane diffusion flame with ammonia seeding. The largest reaction flux is $\mathrm{NH}_{2} \rightarrow \mathrm{NH}$ at $4.2 \mathrm{e}-6$ $(\mathrm{mol} / \mathrm{s})$. Only arrows at least $3 \%$ of the thickest are drawn. This is a superset of Figure $4 \ldots \ldots \ldots \ldots$. . . . . . . . .

6 Temperature and heat release for the simulated flame described in the Appendix. Only the lower third of the computational domain is shown. Dotted lines mark the stoichiometric sheet as determined by $\psi=1 / 2$ in equation (4). . . . . . . . . . . .

Conditional carbon reaction path diagrams for the rich (red) and lean (blue) regions of Figure 6's flame. Only arrows at least 2\% of the thickest are drawn. . . . . . . . . . . .

8 The distribution of fuel and oxidizer for the simulated flame described in the Appendix. Only the lower two-thirds of the computational domain are shown. Dotted lines mark the stoichiometric sheet as determined by Equation 4 's level set $\psi=1 / 2$. . . . . .

9 Conditional carbon reaction path diagrams for portions of Figure 8's flame: the base (red, below $1 \mathrm{~cm}$ in axial position) and higher downstream (blue, above $1 \mathrm{~cm}$ in axial position). Only arrows at least $2 \%$ of the thickest are drawn. . . . . . . . . . . . Oxygen reaction path diagrams of types 0 through 4 . The scale of the type 0 diagram is $1 / 1000$ the scale of the others. In each diagram, only those arrows are drawn that have weight at least $9 \%$ of the thickest $(0.1 \%$ for type 0$)$, and if such an arrow is opposed then its companion is also drawn. . . . . . . . . . 


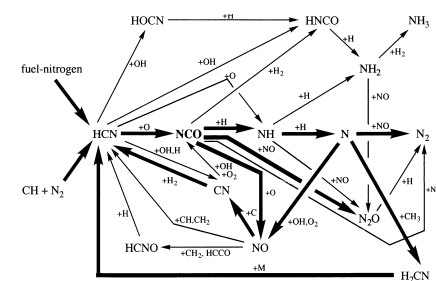

"Reaction scheme showing the major steps in the formation of prompt NO and also the conversion of fuel-nitrogen." From Becker et al. [3, p. 571, fig. 1].

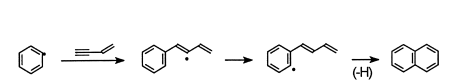

"Ringforming addition of vinylacetylene $\left(\mathrm{C}_{4} \mathrm{H}_{4}\right)$ to aromatic radicals." From Appel et al. [2, p. 128].

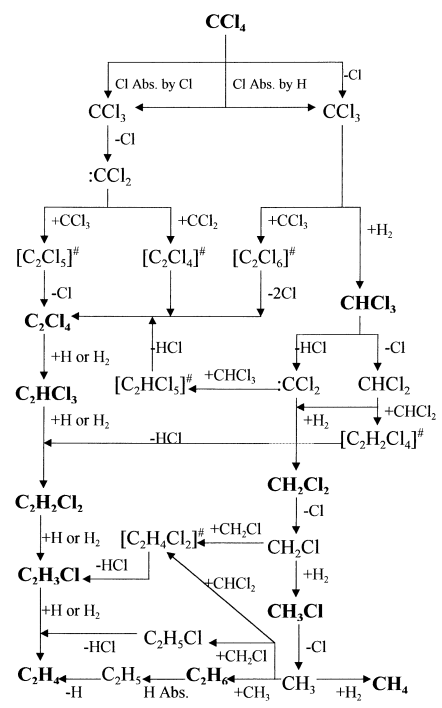

${ }_{\text {CH3 }} \mathrm{H}_{3} \mathrm{H}_{2} \cdot \mathrm{H}^{-}$"Detailed reaction pathways in

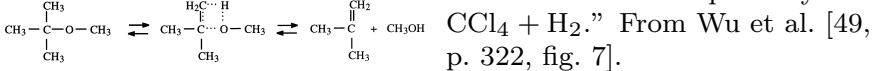
"A molecular four-center elimination reaction [that] in the case of MTBE ... gives isobutene and methanol." From Glaude et al. [20, p. 348].

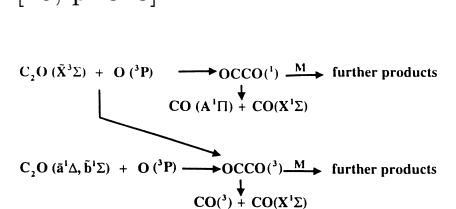

"The scheme [that includes these reactions] is proposed to explain both the CO Fourth Positive and triplet states chemilumines- der low $\mathrm{Cl} / \mathrm{H}$ ratio conditions."
cence." From Fontijn et al. [16, From Werner et al. [45, p. 128, p. 701]. fig. 1]

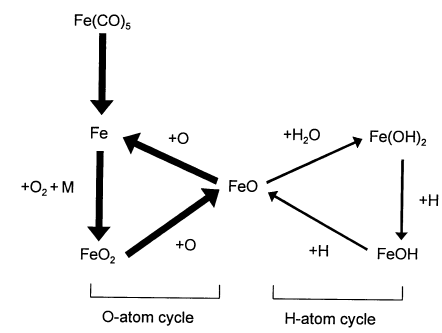

"Schematic diagram of pathways in $\mathrm{CO}-\mathrm{H}_{2}-\mathrm{O}_{2}-\mathrm{N}_{2}$ flames." From Rumminger et al. [34, p. 458, fig. 4].

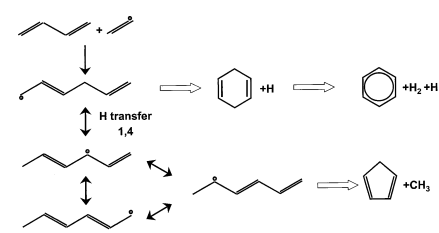

"Reactions adding the vinyl radical to butadiene." From Goldaniga, et al. [21, p. 356, fig. 6].

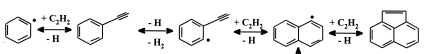

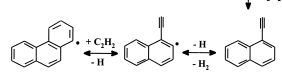

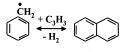

U.

O?

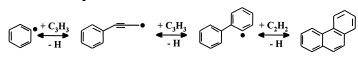

"A schematic diagram illustrating the kinetic pathways for aromatic growth." From D'Anna et al. [11, p. 421 , fig. 1].

Figure 1: Nine "schematic" reaction path diagrams from Combustion and Flame in 2000 . 
(a)

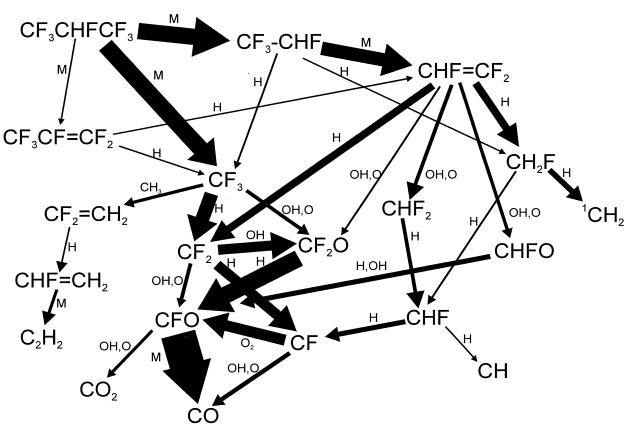

"Reaction pathways of fluorocarbon species in the $\mathrm{CH}_{4} / \mathrm{O}_{2} / \mathrm{C}_{3} \mathrm{HF}_{7}$ flame according to the kinetic mechanism. Arrow thicknesses are proportional to the molar flux of carbon-containing species. The most important reaction partner(s) are written next to each arrow in decreasing order of importance." From Williams et al. [47, p. 169, fig. 9].

(b)

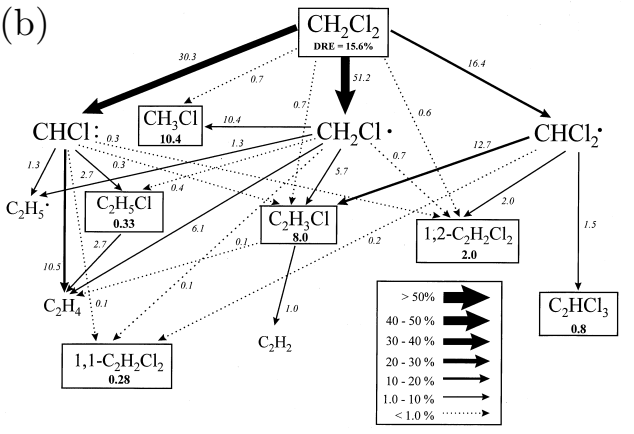

"Reaction pathway diagram, $\Phi=1.1, T_{i n j}=$ $1000 \mathrm{~K}, t_{\text {end }}=0.278 \mathrm{~s}$. Numbers are the percent chlorine reacting through the channel (arrow) and the percent chlorine remaining in stable species (boxes)." From Sgro et al. [35, p. 500, fig. 10].

(c)

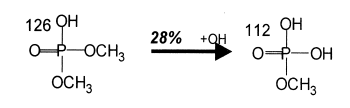

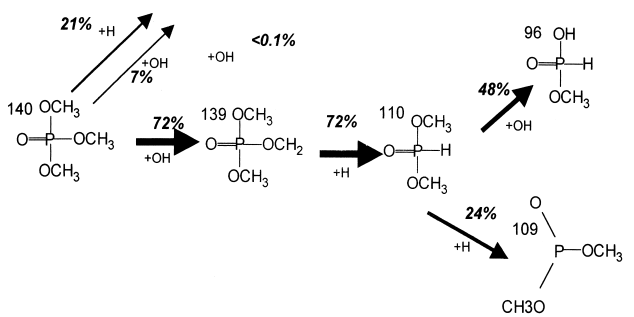

"Integral analysis of consumption rates of TMP, dimethyl phosphite, and $\left(\cdot \mathrm{CH}_{2} \mathrm{O}\right)\left(\mathrm{CH}_{3} \mathrm{O}\right)_{2} \mathrm{PO}$ in a $\mathrm{H}_{2} / \mathrm{O}_{2} / \mathrm{Ar}$ flame." From Korobeinichev et al. [27, p. 605 , fig. 10].
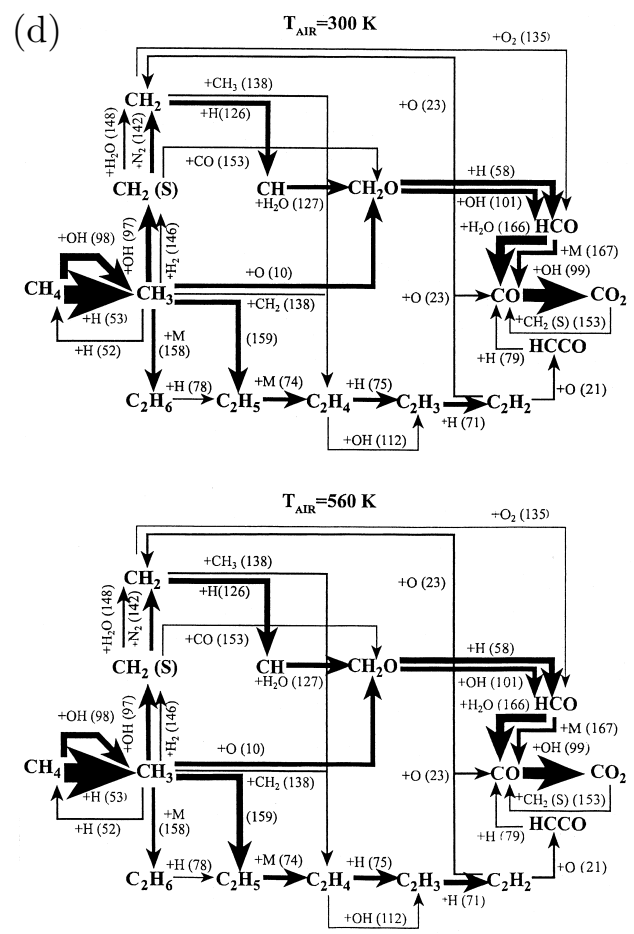

"Quantitative Reaction Path Diagrams (QRPD) showing $\mathrm{CH}_{4}$ conversion to $\mathrm{CO}$ and $\mathrm{CO}_{2}$ including $\mathrm{C}_{1}$ and $\mathrm{C}_{2}$ pathways for two preheat temperatures." From Lim et al. [29, p. 269, fig. 7]

(e)
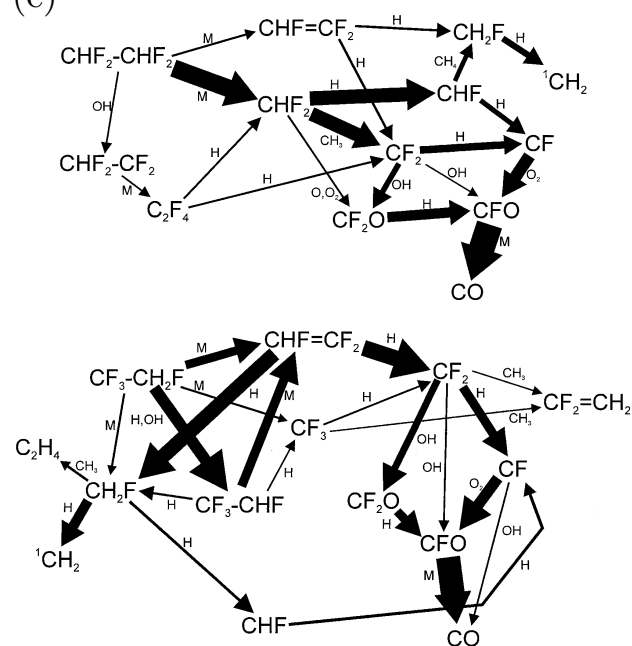

"Reaction pathways for premixed methane/air flames doped with 3.81 mole \% of: (a) HFC-134; and (b) HFC-134a." From Zegers et al. [50, p. 481, fig. 4].

Figure 2: Five "quantitative" reaction path diagrams from Combustion and Flame in 2000. 


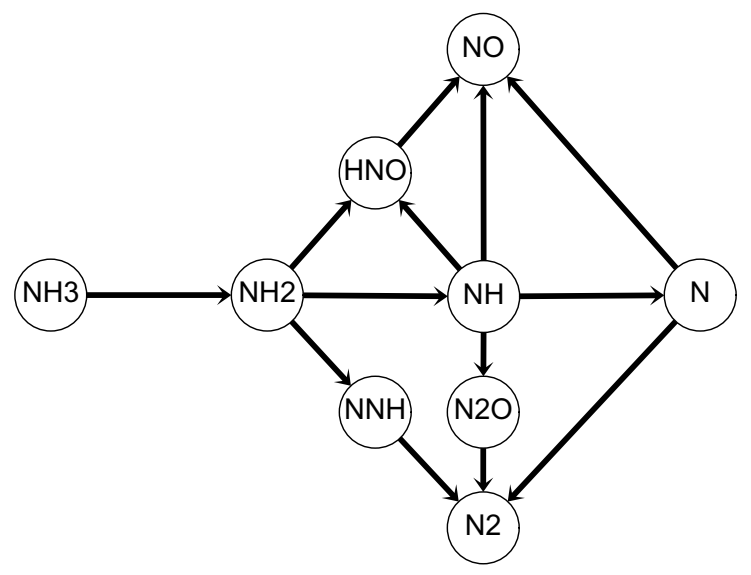

Figure 3: A familiar schematic of ammonia oxidation. This originated in [32] and was redrawn with slight changes in [31].

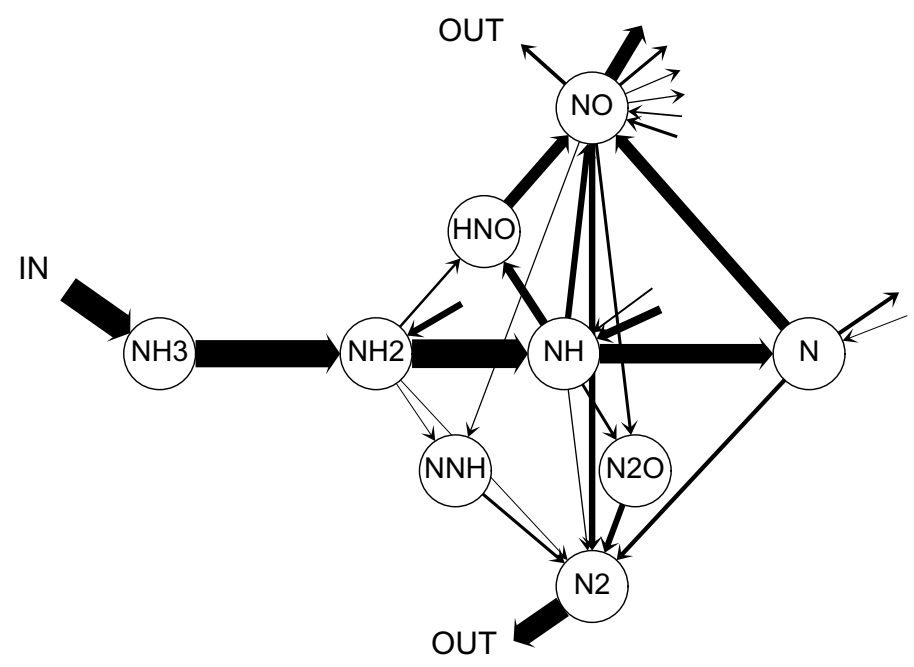

Figure 4: The schematic in Figure 3 is here redrawn with nitrogen reaction paths for an actual methane diffusion flame with ammonia seeding. The unterminated arrows represent paths to or from carbon species. The largest reaction flux is $\mathrm{NH}_{2} \rightarrow \mathrm{NH}$ at 4.2e-6 (mol/s). Only arrows at least $3 \%$ of the thickest are drawn. Figure 5 shows the complete diagram. 


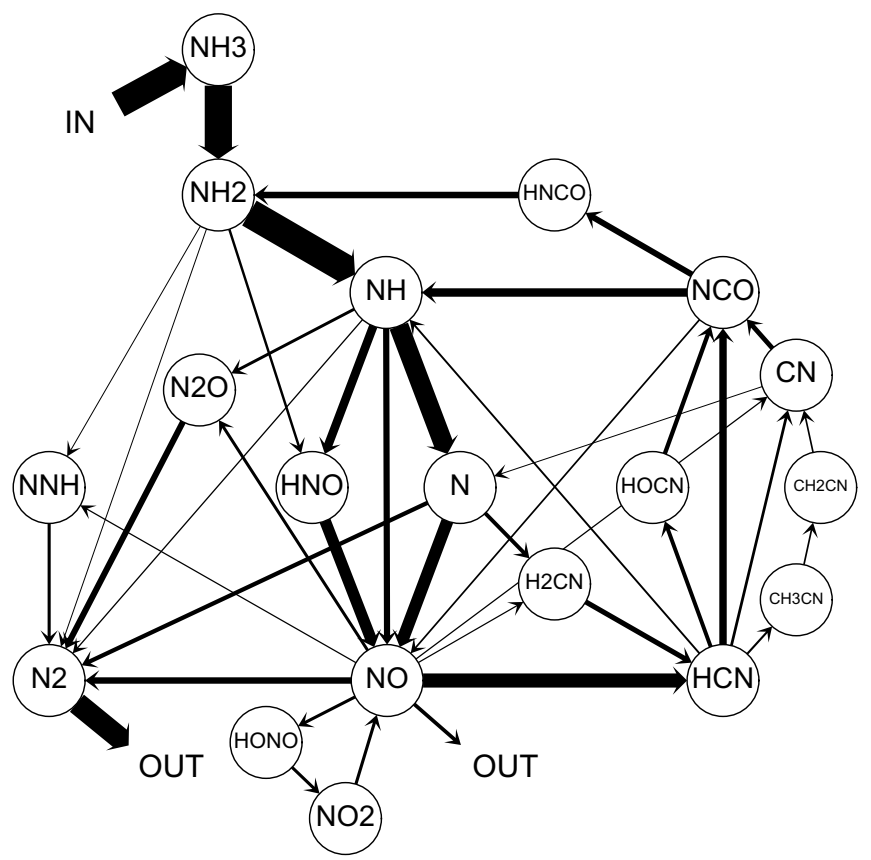

Figure 5: Nitrogen reaction paths in a methane diffusion flame with ammonia seeding. The largest reaction flux is $\mathrm{NH}_{2} \rightarrow \mathrm{NH}$ at 4.2e-6 (mol/s). Only arrows at least $3 \%$ of the thickest are drawn. This is a superset of Figure 4. 


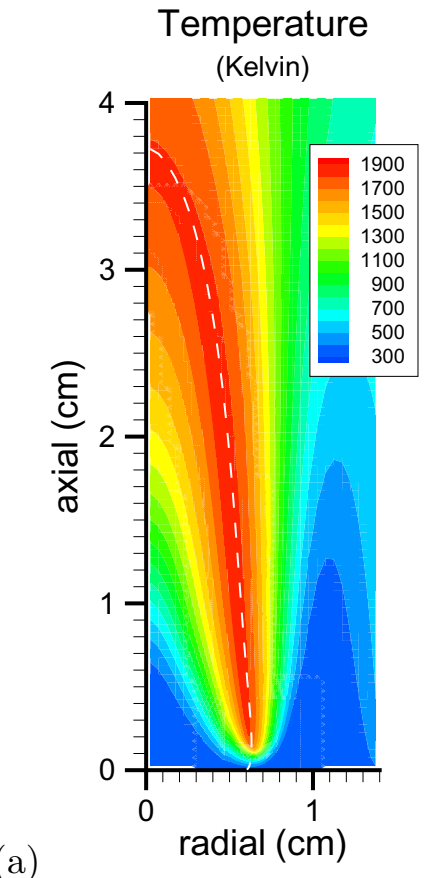

(a)

Figure 6: Temperature and heat release for the simulated flame described in the Appendix. Only the lower third of the computational domain is shown. Dotted lines mark the stoichiometric sheet as determined by $\psi=1 / 2$ in equation (4).

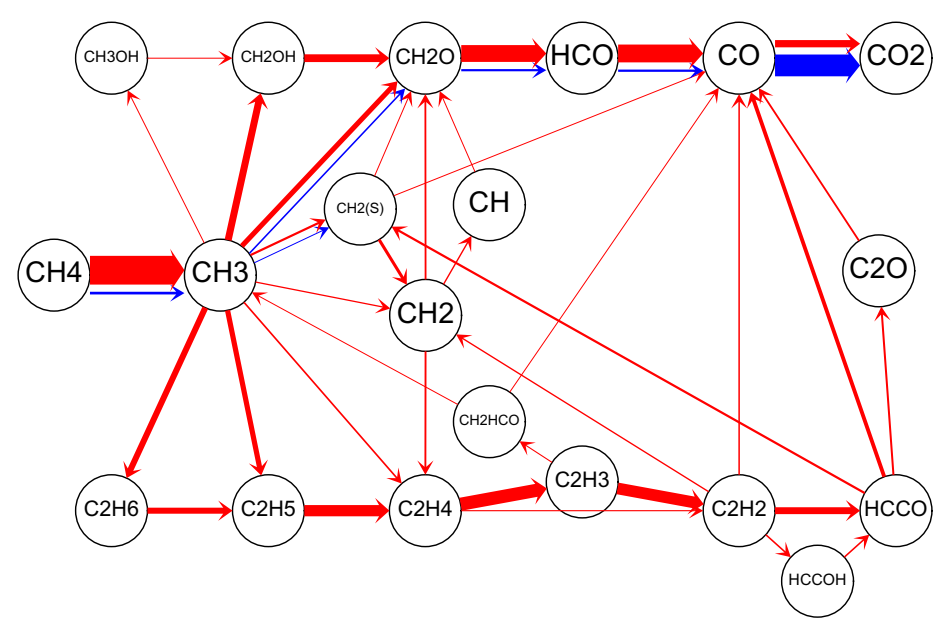

Figure 7: Conditional carbon reaction path diagrams for the rich (red) and lean (blue) regions of Figure 6's flame. Only arrows at least $2 \%$ of the thickest are drawn. 


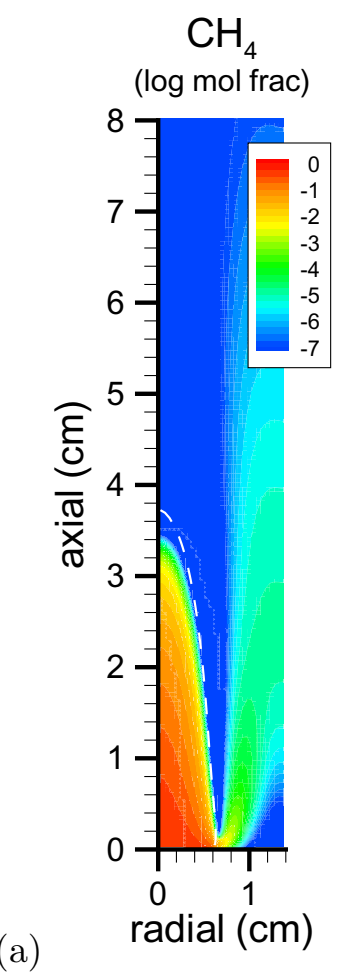

Figure 8: The distribution of fuel and oxidizer for the simulated flame described in the Appendix. Only the lower two-thirds of the computational domain are shown. Dotted lines mark the stoichiometric sheet as determined by Equation 4's level set $\psi=1 / 2$.

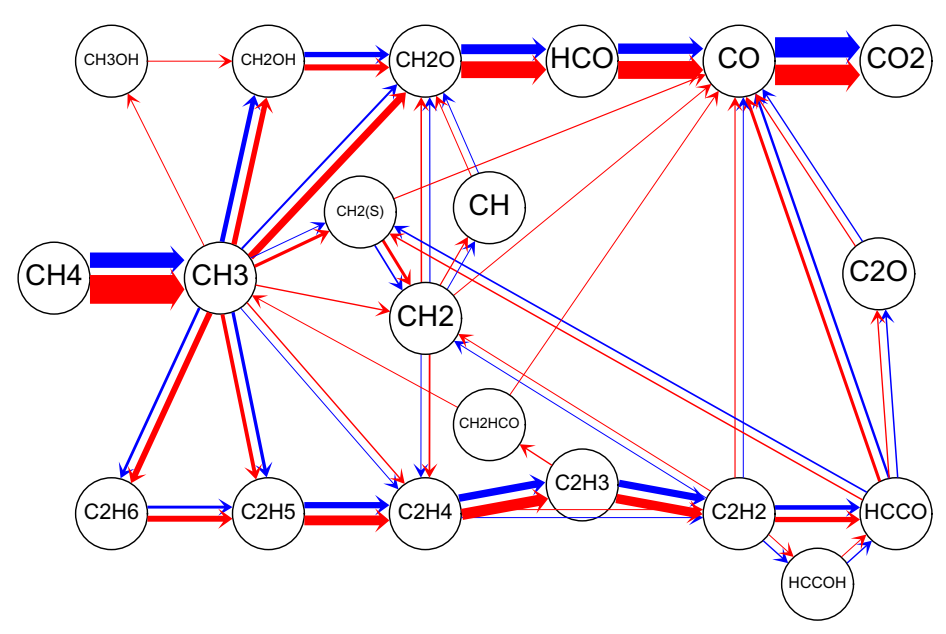

Figure 9: Conditional carbon reaction path diagrams for portions of Figure 8's flame: the base (red, below $1 \mathrm{~cm}$ in axial position) and higher downstream (blue, above $1 \mathrm{~cm}$ in axial position). Only arrows at least $2 \%$ of the thickest are drawn. 
(a) type 0 . separate forward and reverse (b) type 1. any reactions anywhere (c) type 2 . different reactions (d) type 3 . different locations (e) type 4 .

unidirectional

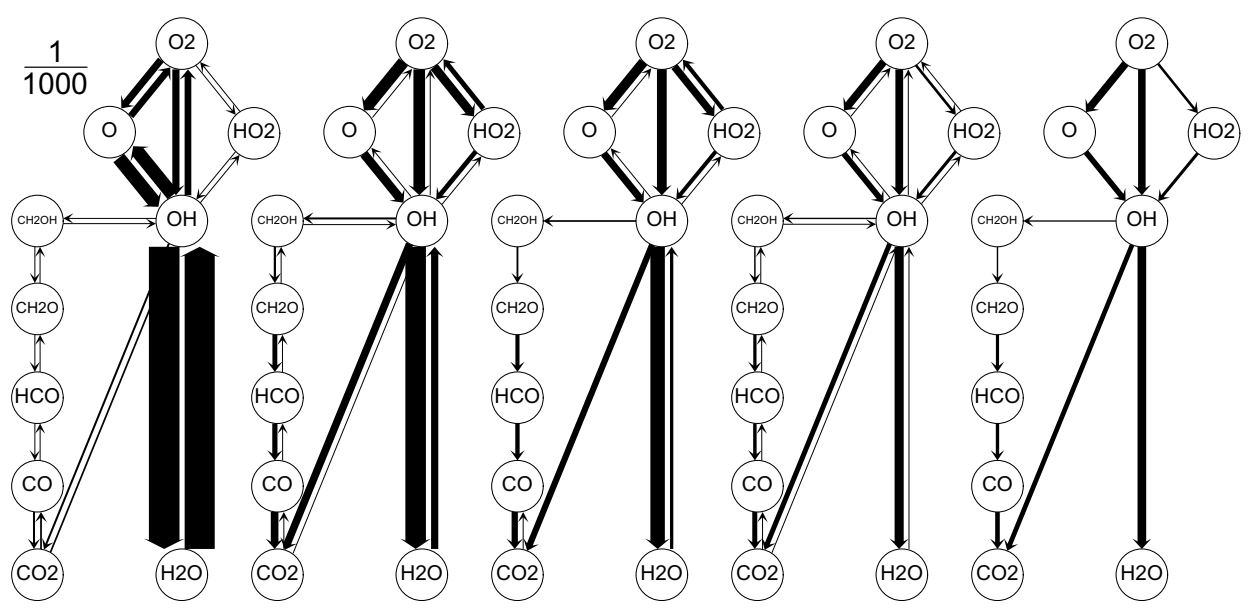

Figure 10: Oxygen reaction path diagrams of types 0 through 4. The scale of the type 0 diagram is 1/1000 the scale of the others. In each diagram, only those arrows are drawn that have weight at least $9 \%$ of the thickest ( $0.1 \%$ for type 0$)$, and if such an arrow is opposed then its companion is also drawn. 


\section{List of Tables}

1 Quantities of reactions that are ambiguous with respect to the disposition of various elements in some well known methane reaction mechanisms. . . . . . . . . . . . . . . .

2 For the paths in Figure 10(b)'s type 1 reaction path diagram, this table shows the percent of each path due to various reactions in the mechanism of Glarborg et al. [18]; only contributions of at least $5 \%$ are listed. . . . . . . . . . . . . . .

3 Reactions involving oxygen and hydrogen in Table 2, which are responsible for many of the paths in Figure 10, ranked by net flux of oxygen atoms and by reaction rate of progress (RRP). Many but not all of these reactions are found in discussions of hydrogen oxidation: G [19], T [43], W [48], WMD [44]. . . . . . . . . . 29 
Table 1: Quantities of reactions that are ambiguous with respect to the disposition of various elements in some well known methane reaction mechanisms.

ambiguous and total reactions involving the element

\begin{tabular}{|l|rr|rr|rr|rr|}
\cline { 2 - 9 } \multicolumn{1}{c|}{} & \multicolumn{2}{c|}{ C } & \multicolumn{2}{c|}{ Hechanism } & \multicolumn{2}{c|}{ N } & \multicolumn{2}{c|}{ O } \\
\hline DRM19 [25] & $\mathbf{4}$ & 65 & $\mathbf{2 0}$ & 82 & & & $\mathbf{1 1}$ & 60 \\
\hline Leeds $[24]$ & $\mathbf{1 8}$ & 164 & $\mathbf{5 6}$ & 186 & & & $\mathbf{2 5}$ & 132 \\
\hline GRI-Mech 3.0 $[36]$ & $\mathbf{1 2}$ & 254 & $\mathbf{8 9}$ & 300 & $\mathbf{1}$ & 106 & $\mathbf{5 1}$ & 253 \\
\hline Glarborg et al. $[18]$ & $\mathbf{3 4}$ & 327 & $\mathbf{1 0 6}$ & 400 & $\mathbf{2 2}$ & 209 & $\mathbf{8 9}$ & 364 \\
\hline
\end{tabular}

Table 2: For the paths in Figure 10(b)'s type 1 reaction path diagram, this table shows the percent of each path due to various reactions in the mechanism of Glarborg et al. [18]; only contributions of at least 5\% are listed.

(100) $\mathrm{OH} \rightarrow \mathrm{H}_{2} \mathrm{O}$

$49 \% \mathrm{OH}+\mathrm{H}_{2} \rightleftharpoons \mathrm{H}_{2} \mathrm{O}+\mathrm{H}$

$13 \% \mathrm{CH}_{4}+\mathrm{OH} \rightleftharpoons \mathrm{CH}_{3}+\mathrm{H}_{2} \mathrm{O}$

$12 \% \mathrm{CH}_{2} \mathrm{O}+\mathrm{OH} \rightleftharpoons \mathrm{HCO}+\mathrm{H}_{2} \mathrm{O}$

$5 \% \mathrm{H}+\mathrm{OH}+\mathrm{M} \rightleftharpoons \mathrm{H}_{2} \mathrm{O}+\mathrm{M}$

$5 \% \mathrm{OH}+\mathrm{HO}_{2} \rightleftharpoons \mathrm{H}_{2} \mathrm{O}+\mathrm{O}_{2}$

(57) $\mathrm{O}_{2} \rightarrow \mathrm{O}$

$97 \% \mathrm{O}_{2}+\mathrm{H} \rightleftharpoons \mathrm{O}+\mathrm{OH}$

(57) $\mathrm{O}_{2} \rightarrow \mathrm{OH}$

$98 \% \mathrm{O}_{2}+\mathrm{H} \rightleftharpoons \mathrm{O}+\mathrm{OH}$

(44) $\mathrm{O} \rightarrow \mathrm{OH}$

$45 \% \mathrm{O}+\mathrm{H}_{2} \mathrm{O} \rightleftharpoons 2 \mathrm{OH}$

$35 \% \mathrm{O}+\mathrm{H}_{2} \rightleftharpoons \mathrm{OH}+\mathrm{H}$

$11 \% \mathrm{O}+\mathrm{HO}_{2} \rightleftharpoons \mathrm{O}_{2}+\mathrm{OH}$

(44) $\mathrm{O}_{2} \rightarrow \mathrm{HO}_{2}$

$47 \% \mathrm{H}+\mathrm{O}_{2}+\mathrm{M} \rightleftharpoons \mathrm{HO}_{2}+\mathrm{M}$

$41 \% \mathrm{H}+\mathrm{O}_{2}+\mathrm{N}_{2} \rightleftharpoons \mathrm{HO}_{2}+\mathrm{N}_{2}$

$6 \% \mathrm{HCO}+\mathrm{O}_{2} \rightleftharpoons \mathrm{HO}_{2}+\mathrm{CO}$

$5 \% \mathrm{CH}_{2} \mathrm{OH}+\mathrm{O}_{2} \rightleftharpoons \mathrm{CH}_{2} \mathrm{O}+\mathrm{HO}_{2}$

(37) $\mathrm{CO} \rightarrow \mathrm{CO}_{2}$

$98 \% \mathrm{CO}+\mathrm{OH} \rightleftharpoons \mathrm{CO}_{2}+\mathrm{H}$

(37) $\mathrm{OH} \rightarrow \mathrm{CO}_{2}$

$100 \% \mathrm{CO}+\mathrm{OH} \rightleftharpoons \mathrm{CO}_{2}+\mathrm{H}$
(35) $\mathrm{H}_{2} \mathrm{O} \rightarrow \mathrm{OH}$

$56 \% \mathrm{O}+\mathrm{H}_{2} \mathrm{O} \rightleftharpoons 2 \mathrm{OH}$

$43 \% \mathrm{H}_{2} \mathrm{O}+\mathrm{H} \rightleftharpoons \mathrm{OH}+\mathrm{H}_{2}$

(25) $\mathrm{HCO} \rightarrow \mathrm{CO}$

$81 \% \mathrm{HCO}+\mathrm{M} \rightleftharpoons \mathrm{H}+\mathrm{CO}+\mathrm{M}$

$5 \% \mathrm{HCO}+\mathrm{O}_{2} \rightleftharpoons \mathrm{HO}_{2}+\mathrm{CO}$

$5 \% \mathrm{HCO}+\mathrm{OH} \rightleftharpoons \mathrm{H}_{2} \mathrm{O}+\mathrm{CO}$

$5 \% \mathrm{HCO}+\mathrm{H} \rightleftharpoons \mathrm{CO}+\mathrm{H}_{2}$

(24) $\mathrm{HO}_{2} \rightarrow \mathrm{O}_{2}$

$41 \% \mathrm{OH}+\mathrm{HO}_{2} \rightleftharpoons \mathrm{H}_{2} \mathrm{O}+\mathrm{O}_{2}$

$39 \% \mathrm{O}+\mathrm{HO}_{2} \rightleftharpoons \mathrm{O}_{2}+\mathrm{OH}$

$20 \% \mathrm{H}+\mathrm{HO}_{2} \rightleftharpoons \mathrm{H}_{2}+\mathrm{O}_{2}$

(24) $\mathrm{CH}_{2} \mathrm{O} \rightarrow \mathrm{HCO}$

$52 \% \mathrm{CH}_{2} \mathrm{O}+\mathrm{OH} \rightleftharpoons \mathrm{HCO}+\mathrm{H}_{2} \mathrm{O}$

$35 \% \mathrm{CH}_{2} \mathrm{O}+\mathrm{H} \rightleftharpoons \mathrm{HCO}+\mathrm{H}_{2}$

$11 \% \mathrm{CH}_{3}+\mathrm{CH}_{2} \mathrm{O} \rightleftharpoons \mathrm{CH}_{4}+\mathrm{HCO}$

(23) $\mathrm{HO}_{2} \rightarrow \mathrm{OH}$

$99 \% \mathrm{H}+\mathrm{HO}_{2} \rightleftharpoons 2 \mathrm{OH}$

(11) $\mathrm{CH}_{2} \mathrm{OH} \rightarrow \mathrm{CH}_{2} \mathrm{O}$

$86 \% \mathrm{CH}_{2} \mathrm{OH}(+\mathrm{M}) \rightleftharpoons \mathrm{CH}_{2} \mathrm{O}+\mathrm{H}(+\mathrm{M})$

$11 \% \mathrm{CH}_{2} \mathrm{OH}+\mathrm{O}_{2} \rightleftharpoons \mathrm{CH}_{2} \mathrm{O}+\mathrm{HO}_{2}$

(10) $\mathrm{OH} \rightarrow \mathrm{CH}_{2} \mathrm{OH}$

$98 \% \mathrm{CH}_{3}+\mathrm{OH} \rightleftharpoons \mathrm{CH}_{2} \mathrm{OH}+\mathrm{H}$ 
Table 3: Reactions involving oxygen and hydrogen in Table 2, which are responsible for many of the paths in Figure 10, ranked by net flux of oxygen atoms and by reaction rate of progress (RRP). Many but not all of these reactions are found in discussions of hydrogen oxidation: G [19], T [43], W [48], WMD [44].

\begin{tabular}{|c|c|c|c|c|}
\hline O flux & RRP & reaction & characterization & cited \\
\hline 100 & 100 & $\mathrm{O}_{2}+\mathrm{H} \rightarrow \mathrm{OH}+\mathrm{O}$ & branching & $\mathrm{G}, \mathrm{T}, \mathrm{W}, \mathrm{WMD}$ \\
\hline 69 & 69 & $\mathrm{H}+\mathrm{O}_{2}+\mathrm{M} \rightarrow \mathrm{HO}_{2}+\mathrm{M}$ & terminating & $\mathrm{G}, \mathrm{T}, \mathrm{W}, \mathrm{WMD}$ \\
\hline 44 & 88 & $\mathrm{OH}+\mathrm{H}_{2} \rightarrow \mathbf{H}_{2} \mathrm{O}+\mathbf{H}$ & propagating & $\mathrm{G}, \mathrm{T}, \mathrm{W}, \mathrm{WMD}$ \\
\hline 42 & 42 & $\mathrm{H}+\mathrm{HO}_{2} \rightarrow 2 \mathrm{OH}$ & branching & $\mathrm{G}, \mathrm{T}$ \\
\hline 35 & 35 & $\mathrm{O}+\mathrm{H}_{2} \mathrm{O} \rightarrow 2 \mathrm{OH}$ & branching & $\mathrm{G}, \mathrm{T}$ \\
\hline 27 & 18 & $\mathrm{OH}+\mathrm{HO}_{2} \rightarrow \mathrm{H}_{2} \mathrm{O}+\mathrm{O}_{2}$ & terminating & \\
\hline 25 & 17 & $\mathrm{O}+\mathrm{HO}_{2} \rightarrow \mathrm{O}_{2}+\mathrm{OH}$ & propagating & $\mathrm{G}, \mathrm{T}$ \\
\hline 14 & 28 & $\mathrm{H}_{2}+\mathrm{O} \rightarrow \mathrm{OH}+\mathrm{H}$ & branching & $\mathrm{G}, \mathrm{T}, \mathrm{W}, \mathrm{WMD}$ \\
\hline 14 & 27 & $\mathbf{O H}+\mathbf{H}_{2} \leftarrow \mathbf{H}_{2} \mathbf{O}+\mathbf{H}$ & propagating & \\
\hline 11 & 11 & $\mathrm{H}+\mathrm{HO}_{2} \rightarrow \mathrm{H}_{2}+\mathrm{O}_{2}$ & terminating & $\mathrm{G}, \mathrm{T}$ \\
\hline 5 & 10 & $\mathrm{OH}+\mathrm{H}+\mathrm{M} \rightarrow \mathrm{H}_{2} \mathrm{O}+\mathrm{M}$ & terminating & $\mathrm{G}, \mathrm{T}, \mathrm{W}$ \\
\hline
\end{tabular}

